\title{
Phenotypic variance, plasticity and heritability estimates of critical thermal limits depend on methodological context
}

\author{
Steven L. Chown ${ }^{1 *}$, Keafon R. Jumbam¹, Jesper G. Sørensen ${ }^{2}$ and John S. Terblanche ${ }^{3}$ \\ ${ }^{1}$ Centre for Invasion Biology, Department of Botany and Zoology, Stellenbosch University, Private Bag X1, Matieland 7602, \\ South Africa; ${ }^{2}$ Aarhus Centre for Environmental Stress Research, Ecology and Genetics, Department of Biological \\ Sciences, University of Aarhus, Ny Munkegade, Building 1540, 8000 Aarhus C, Denmark; and ${ }^{3}$ Department of \\ Conservation Ecology and Entomology, Stellenbosch University, Private Bag X1, Matieland 7602, South Africa
}

\section{Summary}

1. Biologists have long been concerned with measuring thermal performance curves and limits because of their significance to fitness. Basic experimental design may have a marked effect on the outcome of such measurements, and this is true especially of the experimental rates of temperature change used during assessments of critical thermal limits to activity. To date, the focus of work has almost exclusively been on the effects of rate variation on mean values of the critical limits.

2. If the rate of temperature change used in an experimental trial affects not only the trait mean but also its variance, estimates of heritable variation would also be profoundly affected. Moreover, if the outcomes of acclimation are likewise affected by methodological approach, assessment of beneficial acclimation and other hypotheses might also be compromised.

3. In this article, we determined whether this is the case for critical thermal limits using a population of the model species Drosophila melanogaster and the invasive ant species Linepithema humile.

4. We found that effects of the different rates of temperature change are variable among traits and species. However, in general, different rates of temperature change resulted in different phenotypic variances and different estimates of heritability, presuming that genetic variance remains constant. We also found that different rates resulted in different conclusions regarding the responses of the species to acclimation, especially in the case of L. humile.

5. Although it seems premature to dismiss past generalities concerning interspecific and acclimationrelated variation in critical thermal limits, we recommend that conditions during trials be appropriately selected, carefully reported and rigorously controlled.

Key-words: Argentine ant, broad-sense heritability, $\mathrm{CT}_{\mathrm{Max}}, \mathrm{CT}_{\mathrm{Min}}$, heating rate, macrophysiology, phenotypic plasticity

\section{Introduction}

The ability of organisms to remain active across an environmentally appropriate range of temperatures is a significant component of fitness (Kristensen, Loeschcke \& Hoffmann 2007; Loeschcke \& Hoffmann 2007). In consequence, biologists have long been concerned with thermal limits to activity, the shape of thermal performance curves and the mechanisms underlying variation therein (Andrewartha \& Birch 1954; Cossins \& Bowler 1987; Huey \& Kingsolver 1993; Kingsolver \& Huey 1998; Hochachka \& Somero 2002; Ghalambor et al. 2006). Owing partly to concerns about how

*Correspondence author. E-mail: slchown@sun.ac.za organisms will cope with modern climate change (Helmuth, Kingsolver \& Carrington 2005; Parmesan 2006), renewed attention is being given to the nature, form and evolution of thermal performance (Angilletta, Niewiarowski \& Navas 2002; Hoffmann, Sørensen \& Loeschcke 2003a; Chown \& Terblanche 2007; Ghalambor et al. 2007; Pörtner \& Knust 2007). One theme emerging from the recent work is that, during assessments of thermal tolerance, basic experimental design may have a marked effect on the outcome of the work, either because different approaches assess different thermal tolerance traits (Hoffmann et al. 2003a; Chown \& Nicolson 2004; Rako et al. 2007; Kristensen et al. 2008) or because variations on a single approach may affect the end result (e.g. Worland 2005; Rako \& Hoffmann 2006). 
The rate of temperature change adopted in a trial appears to have an especially pronounced effect on estimates of critical thermal limits - a widely used measure of thermal activity range (Lutterschmidt \& Hutchison 1997a; Beitinger, Bennett \& McCauley 2000; Chown \& Nicolson 2004; Somero 2005; Folk, Hoekstra \& Gilchrist 2007). The typical expectation and finding has been that slow rates of temperature change improve either the critical thermal minimum $\left(\mathrm{CT}_{\mathrm{Min}}\right)$ or maximum $\left(\mathrm{CT}_{\mathrm{Max}}\right)$, owing to hardening, a short-term form of phenotypic plasticity (Kay \& Whitford 1978; Kelty \& Lee 2001; Powell \& Bale 2006). However, a recent study has shown that the opposite may also be found. In the tsetse, Glossina pallidipes, slow rates of cooling elevated the $\mathrm{CT}_{\text {Min }}$, while slow rates of warming reduced the $\mathrm{CT}_{\text {Max }}$ (Terblanche et al. 2007a; see also Overgaard et al. 2006, and Cocking 1959; Mora \& Maya 2006 for data on fish). Although these results have highlighted the extent and form of the response of organisms to different rates of temperature change, and the importance of ecologically relevant experimental treatments for assessing thermal tolerance, they have been concerned largely with the mean values of critical limits, and short-term plasticity or hardening under a single set of conditions.

However, when considering the evolution of traits, including those of thermal tolerance, it is not simply the mean value that is significant, but also the variance around that mean (Endler 1986; Garland \& Kelly 2006). Indeed, heritable variation is an important prerequisite for natural selection (Endler 1986; Hoffmann et al. 2003b; Blows \& Hoffmann 2005), a major means by which evolution can take place. Moreover, wherever genetic accommodation or assimilation might be involved in the evolution of new trait values (see West-Eberhard 2003; Pigliucci, Murren \& Schlichting 2006; Ghalambor et al. 2007), how trait values respond to different environmental conditions via phenotypic plasticity is important.

If the rate of temperature change used in an experimental trial assessing $\mathrm{CT}_{\mathrm{Min}}$ or $\mathrm{CT}_{\mathrm{Max}}$ affected not only the mean of the trait, but also its variance, then estimates of heritable variation would also be profoundly affected. For example, if the genetic contribution to phenotypic variance remained relatively constant (Riska, Prout \& Turelli 1989; Yassin et al. 2007), but total phenotypic variance declined with an increase in the rate of temperature change, then estimates of broad sense heritability would increase, recalling (see e.g. Hartl 1980) that broad sense heritability is calculated as:

$h^{2}=\sigma_{g}^{2} / \sigma_{p}^{2}$

eqn 1

Likewise, if the response to acclimation (a longer term form of plasticity than hardening, Hoffmann et al. 2003a) differed significantly among cooling or heating rates then at best interactions among hardening and plasticity would have been detected (e.g. Rako \& Hoffmann 2006). That is, it might be concluded that the extent of acclimation differs significantly depending on the rate of temperature change used, with some rates resulting in larger acclimation effects than others. However, at worst, estimates of the extent and direction of plasticity would be completely confounded. That is, at different rates of change not only might the full extent of plasticity differ, but the acclimation response might be completely different at opposite ends of the rate of temperature change spectrum.

In consequence, and given the pressing significance of understanding the rate at which thermal tolerance traits might change in response to a changing world (Helmuth et al. 2005; Chown \& Terblanche 2007), we here investigate the effects of variable cooling and heating rates on the phenotypic variance of $\mathrm{CT}_{\mathrm{Min}}$ and $\mathrm{CT}_{\mathrm{Max}}$, respectively, and their interactions with acclimation. We include investigations of two species. First, we use a model organism, Drosophila melanogaster, in which hardening has been found when slow rates of cooling are used (Kelty \& Lee 1999, 2001; but see also Overgaard et al. 2006). Second, because it is important to understand how broadly information from model organisms might generalize (Feder, Bennett \& Huey 2000; Chown, Addo-Bediako \& Gaston 2002), we also investigate workers of the Argentine ant, Linepithema humile. This species is not only phylogenetically and ecologically distant from $D$. melanogaster, but is also of considerable global significance as an invasive alien (Tsutsui, Suarez \& Grosberg 2000; Holway et al. 2002), predicted to extend its range as global climates change (Roura-Pascual et al. 2004).

\section{Materials and methods}

\section{STUDY ANIMALS AND ACCLIMATION CONDITIONS}

The D. melanogaster flies used in this study originated from a mass laboratory population established in September 2002 (for details see Bubliy \& Loeschcke 2005). Flies were taken from a line originally selected at constant $30^{\circ} \mathrm{C}$ throughout development every second generation (see Sørensen, Nielsen \& Loeschcke 2007). Briefly, egg-pupal development took place at constant $30^{\circ} \mathrm{C}$ every second generation for 72 generations (36 selection events). Adults and un-selected generations were maintained at $25^{\circ} \mathrm{C}$. Thereafter, the line was kept unselected at $20^{\circ} \mathrm{C}$ for 40 generations. At all times, the line was kept in high numbers $(>1000)$ to decrease drift and all maintenance took place on standard oatmeal-sugar-yeast-agar Drosophila medium at 12L : 12D photoperiodic cycle. Although it might be argued that these flies are somehow unrepresentative of field conditions, this is an especially vexing question. Flies held even under standard laboratory conditions show rapid laboratory adaptation (e.g. Harshman \& Hoffmann 2000; Sgrò \& Partridge 2000) and D. melanogaster is so broadly distributed (see Hoffmann et al. 2003a) that it is difficult to know what representative field conditions might mean. In consequence, we are of the view that providing explicit information on the conditions under which flies have been held is more important than attempting to determine whether or not these are fully representative of field conditions.

The flies were bred under uncrowded conditions (c. 30 individuals per $7 \mathrm{~mL}$ medium) on agar-yeast-sugar-oatmeal medium. Upon emergence, virgin females were collected under $\mathrm{CO}_{2}$ anaesthesia and transferred in groups of 20 to food vials. The vials were distributed equally among three acclimation temperatures of 15,20 or $25^{\circ} \mathrm{C}$ for 5-7 days. This acclimation period was selected because previous investigations of this species and others have shown that it is sufficient for the development of a full response (i.e. ongoing acclimation does not result in further change) to the altered conditions (Hoffmann \& Watson 1993; Terblanche et al. 2006). Containers containing flies 
were all positioned on the same shelf in the incubator eliminating shelf effects.

Whole $L$. humile colonies were collected in the vicinity of Stellenbosch $\left(33^{\circ} 55^{\prime} \mathrm{S} 18^{\circ} 51^{\prime} \mathrm{E}\right)$ and returned to the laboratory within $1-2 \mathrm{~h}$. Colonies were then placed at one of four acclimation temperatures $\left(15,20,25,30^{\circ} \mathrm{C} ; 12 \mathrm{~L}: 12 \mathrm{D}\right.$ photoperiod) for 7 days. Each acclimated colony consisted of $\sim 500$ worker individuals housed in a plastic container $(20 \times 11 \times 8 \mathrm{~cm})$ lined with fluon (Northern Products, Woonsocket, Rhode Island) to prevent ants from escaping (Walters \& Mackay 2003). A colony term was not included in the trials because this species is known to form supercolonies owing to low genetic diversity and selection against colony diversity (Tsutsui et al. 2000, 2003). Because the species is sensitive to dry conditions (Walters \& Mackay 2003; Schilman, Lighton \& Holway 2007), distilled water was made freely available in the containers in the form of moistened cotton wool. Moreover, each small plastic container was housed within a larger one $(25 \times 25 \times 14.5 \mathrm{~cm})$ lined with a sheet of moistened cotton wool. Ants were fed pin-head crickets once every second day, and a $20 \%$ sugar solution was also made freely available. During the acclimation period, containers were rotated daily among shelves within an incubator to avoid shelf effects. Because all workers are females, only females were assessed during the trials.

\section{CRITICAL THERMAL LIMITS}

The start temperature for critical thermal limit experiments in D. melanogaster (mean $\pm \mathrm{SD} ; 1.4 \pm 0.05 \mathrm{mg}, n=57$ ) was $20^{\circ} \mathrm{C}$, thereby eliminating any possible influence of variations in start temperature on experimental outcome (see Terblanche et al. 2007a). Female flies were placed individually in capped, empty, thin-walled $10-\mathrm{mL}$ glass vials. All vials were placed in a horizontal rack and placed in a small tank with a glass front to allow flies to be monitored and scored as they reached their critical thermal limits. The temperature of the water in the tank was controlled by a programmable heating unit (Heto HMT 200 RS, Heto-Holten AS, Allerød, Denmark) which also ensured proper circulation. For tests of $\mathrm{CT}_{\mathrm{Min}}$, the water was cooled by 'cooling fingers' (Hetofrig, Heto, Birkerød, Denmark), with circulation provided by the unit described above. After 6 min equilibration time, temperature was increased $\left(\mathrm{CT}_{\mathrm{Max}}\right)$ or decreased $\left(\mathrm{CT}_{\text {Min }}\right)$ at a constant rate of either $0 \cdot 1,0 \cdot 25$ or $0 \cdot 5^{\circ} \mathrm{C} \min ^{-1}(n=50$ per rate and per trait) until the end point was observed, defined as the onset of muscle spasms in the case of $\mathrm{CT}_{\mathrm{Max}}$ (Lutterschmidt \& Hutchison 1997b) and loss of coordinated muscle function in the case of $\mathrm{CT}_{\text {Min }}$ (observed as an inability of flies to maintain an upright posture) (Klok \& Chown 2003; Chown \& Terblanche 2007). Based on their small body size, the body temperature of the insects was considered equivalent to the chamber temperature (see Stevenson 1985; Terblanche et al. 2007a). This in turn remained very close to water bath temperature, which was used to estimate the end point temperature, owing to the small vial size $(\varnothing \approx 1 \mathrm{~cm}$, with no more than a 5-s delay in equilibration).

For L. humile, an insulated, double-jacketed system which consisted of 11 isolation chambers for individual ants was connected to a programmable water bath (LTC 12 Grant Instruments Ltd., Cambridge, UK), which regulated water temperature around the chambers (see Klok \& Chown 2003). Ten ants were placed singly into the chambers and a 40-gauge copper-constantan (Type T) thermocouple connected to an electronic thermometer (CHY 507 Thermometer, Taiwan) was inserted into a control chamber to monitor chamber temperatures. Based on their small body sizes (mean $\pm \mathrm{SD} ; 0.5 \pm 0.1 \mathrm{mg}, n=20$ ), the body temperatures of the ants were considered equivalent to that of the chamber, with very little equilibration time required. The start temperature for all critical thermal limit experiments was $25^{\circ} \mathrm{C}$, which was maintained for $6 \mathrm{~min}$, thereby eliminating any possible influence of variation in start temperature on the experimental outcome. Thereafter, temperature was increased $\left(\mathrm{CT}_{\mathrm{Max}}\right)$ or decreased $\left(\mathrm{CT}_{\mathrm{Min}}\right)$ at a constant rate of either $0 \cdot 05,0 \cdot 1,0 \cdot 25$ or $0.5{ }^{\circ} \mathrm{C} \mathrm{min}{ }^{-1}$ until the end point was observed, defined as above (and observed as the loss of righting response and an inability of ants to retract their legs in a coordinated fashion when stimulated for $\mathrm{CT}_{\mathrm{Min}}$, and the onset of muscle spasms for $\mathrm{CT}_{\mathrm{Max}}$ ). For each trait, for each rate, and for each acclimation temperature, the trials were repeated until $n \sim 50$.

\section{STATISTICAL ANALYSES}

For each species, the effects of rate and acclimation temperature on each of the traits were assessed using a generalized linear model assuming a normal distribution of errors and using an identity link function. Initial investigations of normality using Shapiro-Wilks tests indicated that in a few instances, distributions deviated from normality. Hence, we did not use a general linear model or an ordered factor, orthogonal polynomial contrast ANOvA. The latter analysis is especially sensitive to departures from normality, while the others are less so (Quinn \& Keough 2002; Littell, Stroup \& Freund 2002). To assess the extent to which variances differed among the rate groups within each acclimation treatment, for each species, Levene's test was used, which is much less sensitive to departures from normality than others such as Bartlett's test (Quinn \& Keough 2002).

\section{Results}

In D. melanogaster, both acclimation temperature and rate of warming significantly affected $\mathrm{CT}_{\text {Max }}$ (Table 1 ). The rate of warming had a large, positive effect on $\mathrm{CT}_{\mathrm{Max}}$, whereas the effect of acclimation temperature was smaller and more complex, but largely similar irrespective of the rate of warming (i.e. the interaction effect was not significant) (Fig. 1a). For $\mathrm{CT}_{\text {Min }}$, the largest effect was that of acclimation, with low temperature acclimation reducing the $\mathrm{CT}_{\mathrm{Min}}$ by comparison with higher acclimation temperatures (Fig. 1b). By contrast, rate had a much smaller, though significant positive effect on $\mathrm{CT}_{\text {Min }}$, such that slower rates of change led to lower $\mathrm{CT}_{\mathrm{Min}}$ values. The interaction term was not significant (Table 1).

Table 1. Outcome of the generalized linear model of the effects of acclimation temperature and rate of temperature change on $\mathrm{CT}_{\mathrm{Max}}$ and $\mathrm{CT}_{\mathrm{Min}}$ in Drosophila melanogaster

\begin{tabular}{|c|c|c|c|}
\hline Trait & d.f. & $\chi^{2}$ & $P$ \\
\hline \multicolumn{4}{|l|}{$\mathrm{CT}_{\mathrm{Max}}$} \\
\hline Acclimation & 2 & $29 \cdot 8$ & $<0.0001$ \\
\hline Rate & 2 & $242 \cdot 5$ & $<0.0001$ \\
\hline Acclimation $\times$ rate & 4 & $2 \cdot 66$ & 0.62 \\
\hline Deviance/d.f. & \multicolumn{3}{|c|}{$147 \cdot 9 / 441=0 \cdot 34$} \\
\hline \multicolumn{4}{|l|}{$\mathrm{CT}_{\mathrm{Min}}$} \\
\hline Acclimation & 2 & $512 \cdot 2$ & $<0.0001$ \\
\hline Rate & 2 & $42 \cdot 0$ & $<0.0001$ \\
\hline Acclimation $\times$ rate & 4 & $4 \cdot 7$ & $0 \cdot 319$ \\
\hline Deviance/d.f. & \multicolumn{3}{|c|}{$229 \cdot 58 / 441=0 \cdot 52$} \\
\hline
\end{tabular}


(a)

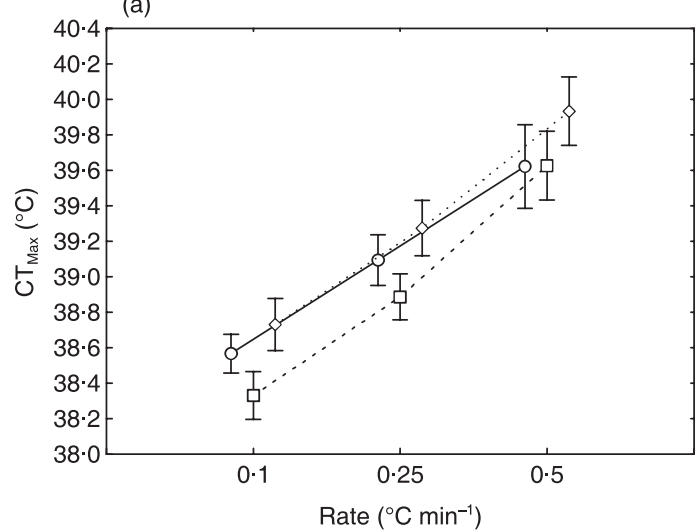

(c)

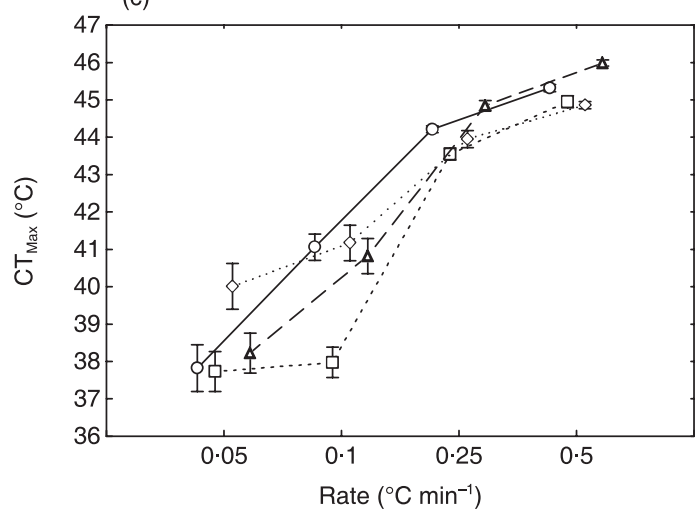

(b)

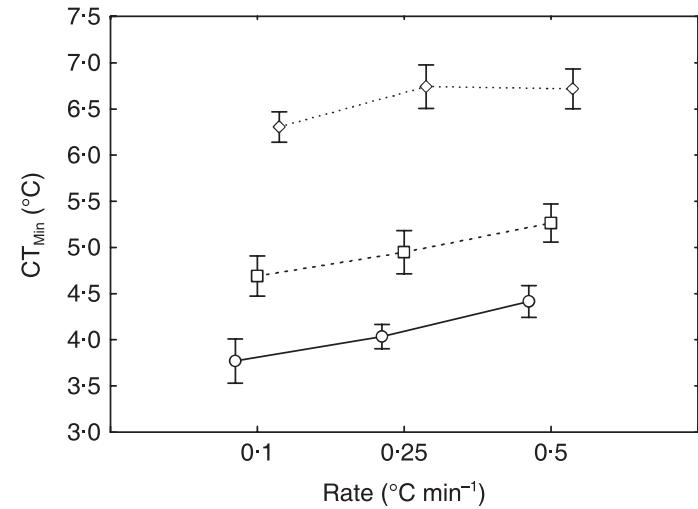

(d)

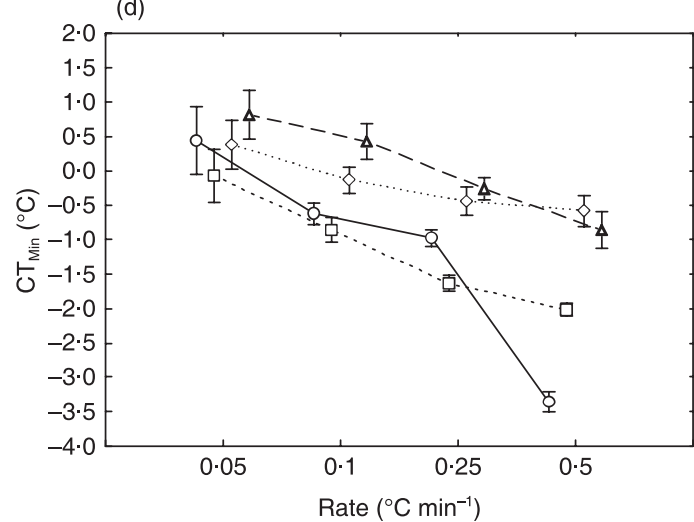

Fig. 1. The effect of acclimation temperature and rate of temperature change on (a) $\mathrm{CT}_{\mathrm{Max}}$ and (b) $\mathrm{CT}_{\mathrm{Min}}$ in Drosophila melanogaster, and (c) $\mathrm{CT}_{\text {Max }}$ and (d) $\mathrm{CT}_{\text {Min }}$ in Linepithema humile. Acclimation treatments are circles, $15{ }^{\circ} \mathrm{C}$; squares, $20{ }^{\circ} \mathrm{C}$; diamonds, $25^{\circ} \mathrm{C}$; triangles, $30{ }^{\circ} \mathrm{C}$. Data shown are means $\pm \mathrm{SE}$, and symbols at each rate are staggered to ease interpretation.

Table 2. Outcome of a generalized linear model of the effects of acclimation temperature and rate of temperature change on $\mathrm{CT}_{\mathrm{Max}}$ and $\mathrm{CT}_{\mathrm{Min}}$ in Linepithema humile

\begin{tabular}{llcl}
\hline Trait & d.f. & $\chi^{2}$ & $P$ \\
\hline $\mathrm{CT}_{\text {Max }}$ & & & \\
$\quad$ Acclimation & 3 & 148.7 & $<0.0001$ \\
$\quad$ Rate & 3 & $1372 \cdot 4$ & $<0.0001$ \\
$\quad$ Acclimation $\times$ rate & 9 & 174.5 & $<0.0001$ \\
$\quad$ Deviance/d.f. & $1305 \cdot 2 / 774=1.69$ & \\
$\mathrm{CT}_{\text {Min }}$ & & & \\
Acclimation & 3 & 244.3 & $<0.0001$ \\
Rate & 3 & 441.3 & $<0.0001$ \\
Acclimation $\times$ rate & 9 & 157.8 & $<0.0001$ \\
Deviance/d.f. & $620.9 / 774=0.80$ & \\
\hline
\end{tabular}

Acclimation temperature and rate of temperature change affected both $\mathrm{CT}_{\mathrm{Max}}$ and $\mathrm{CT}_{\mathrm{Min}}$ in L. humile (Table 2). For $\mathrm{CT}_{\mathrm{Max}}$, the effect of rate of temperature change was positive and larger than that of acclimation temperature, which had a complex effect that varied depending on the rate of temperature change (Fig. 1c). In the case of $\mathrm{CT}_{\mathrm{Min}}$, the effect of rate of temperature change was negative. Moreover, the positive interaction meant the effect of acclimation temperature was small at the slowest cooling rates, whereas it was large at the fastest ones (Fig. 1d), the opposite of what was found for $\mathrm{CT}_{\text {Max }}$.

The extent to which variances were heterogeneous among rates within acclimation treatments varied with the species and with the trait (Figs $2 \& 3$, see also Figs S1-4 of the Supporting Information). In D. melanogaster, Levene's test was not significant for $\mathrm{CT}_{\mathrm{Min}}$ across rates within any of the acclimation treatments (Table 3 ). However, across the full range of acclimation treatments and rates, variances were heterogeneous (Levene's test $F_{(15,774)}=13.86, P<0.0001$ ). In contrast, variances were significantly heterogenous for $\mathrm{CT}_{\text {Max }}$ within each acclimation treatment (Table 3). Variance was largest at the fastest rate of warming, although it was marginally non-significant following acclimation at $25^{\circ} \mathrm{C}$ (Fig. 2a and Fig. S1 of the Supporting Information). In the case of L. humile, although variances in $\mathrm{CT}_{\mathrm{Max}}$ were heterogeneous among rates within acclimation treatments (Table 3 ), they showed the opposite trend to that found in D. melanogaster. That is, variances were largest at the slowest rates of warming, irrespective of acclimation temperature (Fig. 3a and Fig. S3 of the Supporting Information). Likewise, in the case of $\mathrm{CT}_{\mathrm{Min}}$ the slowest rates of cooling resulted in the largest variances (Table 3, Fig. 3b and Fig. S4 of the Supporting Information). This effect was somewhat attenuated at the highest acclimation temperatures. 
(a)

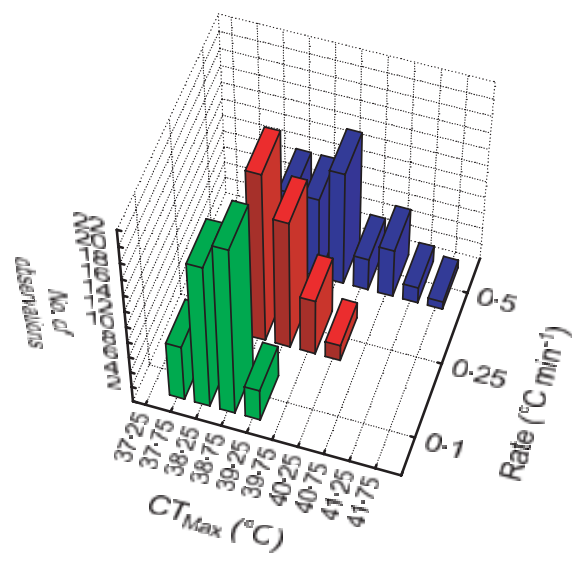

(b)

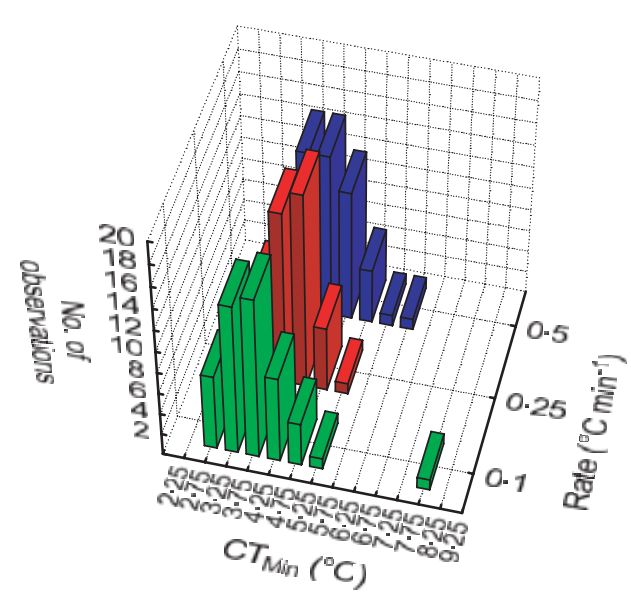

Fig. 2. Frequency distributions of (a) $\mathrm{CT}_{\mathrm{Max}}$ and (b) $\mathrm{CT}_{\mathrm{Min}}$ at different rates of temperature change following acclimation to $15^{\circ} \mathrm{C}$ in Drosophila melanogaster. Frequency distributions for these traits following the other acclimation treatments can be found in Figs S1 and S2 of the Supporting Information.
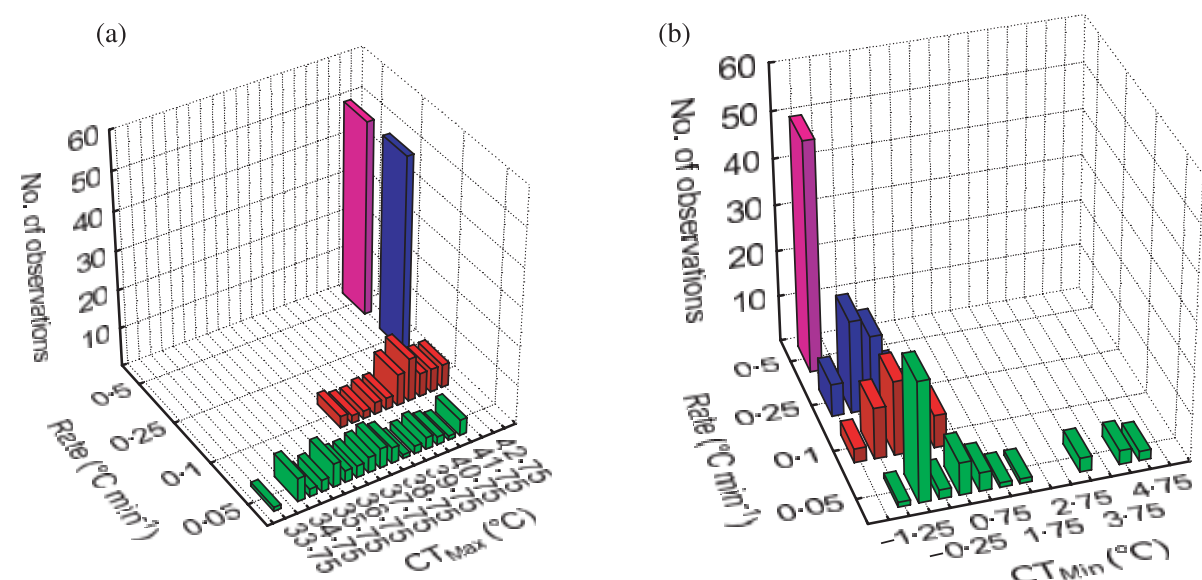

Fig. 3. Frequency distributions of (a) $\mathrm{CT}_{\mathrm{Max}}$ and (b) $\mathrm{CT}_{\mathrm{Min}}$ at different rates of temperature change following acclimation to $15^{\circ} \mathrm{C}$ in Linepithema humile. Frequency distributions for these traits following the other acclimation treatments can be found in Figs S3 and S4 of the Supporting Information.

\section{Discussion}

Typically it has been argued that slow rates of change enable some form of hardening, which results in an increase in $\mathrm{CT}_{\text {Max }}$ or a decline in $\mathrm{CT}_{\text {Min }}$ (Kay \& Whitford 1978; Kelty \& Lee 1999, 2001; Powell \& Bale 2006). Our results bore out these arguments only for $\mathrm{CT}_{\mathrm{Min}}$ in $D$. melanogaster, in keeping with previous findings for this species (Kelty \& Lee 1999). However, the effect size here $\left(c .0 \cdot 5^{\circ} \mathrm{C}\right)$ was much smaller than that found previously $\left(2 \cdot 6^{\circ} \mathrm{C}\right.$, over rates varying from $0 \cdot 1$ to $1 \cdot 0{ }^{\circ} \mathrm{C} \mathrm{min}^{-1}$ ) possibly reflecting differences between the flies used here and the Oregon-R strain used by Kelty \& Lee (1999). Which outcome should be considered 'representative' for the species is more difficult to discern because even the absence of specific selection regimes may result in laboratory adaptation (see e.g. Harshman \& Hoffmann 2000), and because the species is so widespread globally.
By contrast, faster rates of heating resulted in higher $\mathrm{CT}_{\text {Max }}$ values in D. melanogaster and in L. humile, and faster rates of cooling lowered $\mathrm{CT}_{\text {Min }}$ in the latter. These findings are in keeping with previous results for tsetse (Terblanche et al. 2007a). What the ultimate cause is of the amongspecies difference in the response of $\mathrm{CT}_{\mathrm{Min}}$ to rate variation remains unclear. It may well have to do with the absence of rapid cold hardening (Lee, Chen \& Denlinger 1987) in more tropical species (Terblanche et al. 2007a), or perhaps its absence in species that show substantial behavioural avoidance of low temperature extremes (e.g. Hawes et al. 2006; Terblanche, Marais \& Chown 2007b), as does the Argentine ant (Witt \& Giliomee 1999; Krushelnycky et al. 2005). Whatever the explanation for the variation among rates, it is clear that future studies can ill afford to neglect the effects of the experimental protocol on the resultant outcome. 
Table 3. Outcome of Levene's test for homogeneity of variances among rates of temperature change within each acclimation treatment for $\mathrm{CT}_{\mathrm{Max}}$ and $\mathrm{CT}_{\mathrm{Min}}$ in Drosophila melanogaster and Linepithema humile

\begin{tabular}{lrll}
\hline Species/acclimation treatment & $F$ & $P$ & d.f. \\
\hline D. melanogaster $\mathrm{CT}_{\text {Max }}$ & & & \\
$15^{\circ} \mathrm{C}$ & $9 \cdot 17$ & $0 \cdot 0002$ & 2,147 \\
$20^{\circ} \mathrm{C}$ & $5 \cdot 96$ & $0 \cdot 0032$ & 2,147 \\
$25{ }^{\circ} \mathrm{C}$ & $2 \cdot 57$ & $0 \cdot 0797$ & 2,147 \\
D. melanogaster $\mathrm{CT}_{\text {Min }}$ & & & \\
$15{ }^{\circ} \mathrm{C}$ & $2 \cdot 22$ & $0 \cdot 113$ & 2,147 \\
$20^{\circ} \mathrm{C}$ & $0 \cdot 01$ & $0 \cdot 988$ & 2,147 \\
$25{ }^{\circ} \mathrm{C}$ & $3 \cdot 04$ & $0 \cdot 051$ & 2,147 \\
L. humile $\mathrm{CT}_{\text {Max }}$ & & & \\
$15^{\circ} \mathrm{C}$ & $54 \cdot 41$ & $0 \cdot 0001$ & 3,196 \\
$20^{\circ} \mathrm{C}$ & $27 \cdot 41$ & $0 \cdot 0001$ & 3,192 \\
$25{ }^{\circ} \mathrm{C}$ & $51 \cdot 31$ & $0 \cdot 0001$ & 3,192 \\
$30^{\circ} \mathrm{C}$ & $56 \cdot 53$ & $0 \cdot 0001$ & 3,194 \\
L. humile $\mathrm{CT}_{\text {Min }}$ & & & \\
$15^{\circ} \mathrm{C}$ & 28.93 & $0 \cdot 0001$ & 3,195 \\
$20^{\circ} \mathrm{C}$ & $22 \cdot 71$ & $0 \cdot 0001$ & 3,195 \\
$25^{\circ} \mathrm{C}$ & $5 \cdot 33$ & $0 \cdot 0015$ & 3,190 \\
$30^{\circ} \mathrm{C}$ & $5 \cdot 87$ & $0 \cdot 0007$ & 3,194 \\
\hline
\end{tabular}

Indeed, these effects extend far beyond a change in means. Here, variances in both traits were affected substantially by the rate of temperature change adopted and this differed markedly among the species, traits, and to a smaller extent among the acclimation treatments. In D. melanogaster, the effects of rate on the variance of $\mathrm{CT}_{\text {Min }}$ were small and apparent only across the full trial, whereas increasing rates of temperature change resulted in increasing variances for $\mathrm{CT}_{\mathrm{Max}}$. By contrast, in L. humile, higher rates of change resulted in smaller variances of the critical thermal limit estimates. Why these differences among species and traits exist is not yet clear, although the differences among traits and species suggest that the changing variances are not simply an artefact of changing experimental durations. Nonetheless, the implications of these changing variances are important. If the genetic contribution to phenotypic variance remains constant (Riska et al. 1989; Yassin et al. 2007), which presumably it would amongst a random sample of individuals exposed to different rates of temperature change, then a decline in phenotypic variance (either with an increase or a decline in rate of temperature change as documented here) would lead to a substantial change in the estimate of heritability (see eqn 1). For example, following acclimation to $15^{\circ} \mathrm{C}$, the variance in $\mathrm{CT}_{\mathrm{Max}}$ in $L$. humile ranged from 4.9 (at $0.05{ }^{\circ} \mathrm{C} \mathrm{min}{ }^{-1}$ ) to $0.11{ }^{\circ} \mathrm{C}$ (at $0.5^{\circ} \mathrm{C} \mathrm{min}^{-1}$ ). If the genetic variance is assumed to have a value of $0 \cdot 1$, then the estimate of broad sense heritability would vary from 0.02 at the slowest rate of change to 0.91 at the fastest. In other words, one set of experiments might lead researchers to conclude that $\mathrm{CT}_{\mathrm{Max}}$ is not heritable, while another might provide evidence that it is a highly heritable trait. The same problem would apply in the case of narrow sense heritability, and particularly when the observed phenotypic variance is used in preference to the summed values of additive and residual variance (see Wilson
2008). Both conclusions would have obvious downstream effects on predictions about the extent to which the trait might evolve (Endler 1986; Falconer \& Mackay 1996; Blows \& Hoffmann 2005). Clearly, a different set of experiments involving laboratory selection (Gibbs 1999), full sib investigations (Falconer \& Mackay 1996) or isofemale lines (Hoffmann \& Parsons 1988) could be designed to assess realized heritability. However, unless the phenotypic variance was partitioned identically in each case, the experimental rates of change would still have an effect on estimates of heritability. We know of no work that has sought to investigate the effects of rate of temperature change on variance partitioning using laboratory selection, full sib assessments or isofemale lines.

In addition to their effects on variances, changing rates also had significant and pronounced effects on estimates of the response to acclimation of $\mathrm{CT}_{\mathrm{Min}}$ and $\mathrm{CT}_{\mathrm{Max}}$ in L. humile. Previous work investigating the effects of acclimation on critical thermal limits, typically undertaken using rates $\geq 0.25^{\circ} \mathrm{C} \mathrm{min}^{-1}$, has demonstrated that $\mathrm{CT}_{\mathrm{Max}}$ is much less responsive to acclimation treatments than is $\mathrm{CT}_{\text {Min }}$ (e.g. Klok \& Chown 2003; Terblanche et al. 2006). These findings are largely in keeping with what we documented here for L. humile, and with other investigations of geographic trait variation and responses to selection (e.g. Gilchrist, Huey \& Partridge 1997; Kingsolver \& Huey 1998; Addo-Bediako, Chown \& Gaston 2000; Chown 2001; Kimura 2004). Nonetheless, they also illustrate that different species may have dissimilar responses to both experimental conditions and natural environmental variation (compare the above with the outcomes of work by Hoffmann, Anderson \& Hallas 2002 and Calosi, Bilton \& Spicer 2008).

Perhaps more importantly, this study has demonstrated that the experimental approaches adopted might substantially affect the conclusions drawn from a particular investigation of acclimation effects on thermal tolerance means and variances, over and above the differences expected from assessments of traits that have different genetic underpinnings (Rako et al. 2007). Although it seems premature to dismiss past generalities concerning interspecific and acclimationrelated variation in critical thermal limits based on this finding, the latter does beg the question of how different present understanding would be if previous studies had used rates relevant to the environment within which the species occur. Clearly, merit exists in using standardized methods for comparing species and populations, but strong arguments can also be presented in favour of investigating thermal limits using environmentally relevant conditions (Sinclair 2001). Resolving these questions remains a key issue for macrophysiology (Chown, Gaston \& Robinson 2004; Chown \& Gaston 2008).

Of course, it may be argued that other methods of assessing dynamic thermal tolerance traits (see Lutterschmidt \& Hutchison 1997a), such as chill coma recovery (David et al. 1998), should be used to avoid problems associated with rates of change used in critical thermal limit experiments. However, because cooling and heating rates are involved in these 
assessments too, the problem is unlikely to be resolved. Another alternative might be to suggest that dynamic assessments of thermal tolerance limits should not be used at all. However, because static and dynamic methods are likely to be assessing completely different basal and induced traits, that have different genetic bases (Rako et al. 2007), such an approach would not resolve the matter either. To our minds, the most appropriate approach would either be to provide a comparison of outcomes using both a standard rate and an environmentally relevant one, or to be explicit about what the purpose of the work is. Later, comparative investigations would then simply have to include heating or cooling rates in the statistical analyses, much as census area is included in comparisons of avifaunal density because of the profound effect that area has on estimates of density (Gaston, Blackburn \& Gregory 1999).

\section{Acknowledgments}

We thank Susan Jackson and Elrike Marais for advice, assistance and discussion, Volker Loeschcke for the use of the Drosophila line, and Torsten Kristensen for mass data. We thank two referees and Frank Messina for their useful comments which improved the manuscript. Funding was provided by the Danish Natural Sciences Research Council (J.G.S.) and partially by NRF Grant FA2004032000006

\section{References}

Addo-Bediako, A., Chown, S.L. \& Gaston, K.J. (2000) Thermal tolerance, climatic variability and latitude. Proceedings of the Royal Society of London $B, 267,739-745$.

Andrewartha, H.G. \& Birch, L.C. (1954) The Distribution and Abundance of Animals. University of Chicago Press, Chicago.

Angilletta, M.J., Niewiarowski, P.H. \& Navas, C.A. (2002) The evolution of thermal physiology in ectotherms. Journal of Thermal Biology, 27, 249-268.

Beitinger, T.L., Bennett, W.A. \& McCauley, R.W. 2000. Temperature tolerance of North American freshwater fishes exposed to dynamic changes in temperature. Environmental Biology of Fish, 58, 237-275.

Blows, M.W. \& Hoffmann, A.A. (2005) A reassessment of genetic limits to evolutionary change. Ecology 86, 1371-1384.

Bubliy, O.A. \& Loeschcke V. (2005) Correlated responses to selection for stress resistance and longevity in a laboratory population of Drosophila melanogaster. Journal of Evolutionary Biology, 18, 789-803.

Calosi, P., Bilton, D.T. \& Spicer, J.I. (2008) Thermal tolerance, acclimatory capacity and vulnerability to global climate change. Biology Letters, 4, 99 102.

Chown, S.L. (2001) Physiological variation in insects: hierarchical levels and implications. Journal of Insect Physiology, 47, 649-660.

Chown, S.L., Addo-Bediako, A. \& Gaston, K.J. (2002) Physiological variation in insects: large-scale patterns and their implications. Comparative Biochemistry and Physiology B, 131, 587-602.

Chown, S.L. \& Gaston, K.J. (2008) Macrophysiology for a changing world. Proceedings of the Royal Society of London B, 275, 1469-1478.

Chown, S.L., Gaston, K.J. \& Robinson, D. (2004) Macrophysiology: large-scale patterns in physiological traits and their ecological implications. Functional Ecology, 18, 159-167.

Chown, S.L. \& Nicolson, S.W. (2004) Insect Physiological Ecology. Mechanisms and Patterns. Oxford University Press, Oxford

Chown, S.L. \& Terblanche, J.S. (2007) Physiological diversity in insects: ecological and evolutionary contexts. Advances in Insect Physiology, 33, 50152.

Cocking, A.W. 1959. The effects of high temperatures on roach. II. The effects of temperature increasing at a known constant rate. Journal of Experimental Biology, 36, 217-226.

Cossins, A.R. \& Bowler, K. (1987) Temperature Biology of Animals. Chapman and Hall, London.

David, J.R., Gibert, P., Pla, E., Petavy, G., Karan, D. \& Moreteau, B. (1998) Cold stress tolerance in Drosophila: analysis of chill coma recovery in $D$. melanogaster. Journal of Thermal Biology, 23, 291-299.
Endler, J.A. (1986) Natural Selection in the Wild. Princeton University Press, Princeton.

Falconer, D.S. \& Mackay, T.F.C. (1996) Introduction to Quantitative Genetics. Pearson Education Limited, Harlow.

Feder, M.E., Bennett, A.F. \& Huey, R.B. (2000) Evolutionary physiology. Annual Review of Ecology and Systematics, 31, 315-341.

Folk, D.G., Hoekstra, L.A. \& Gilchrist, G.W. (2007) Critical thermal maxima in knockdown-selected Drosophila: are thermal endpoints correlated? Journal of Experimental Biology, 210, 2649-2656.

Garland, T. \& Kelly, S.A. (2006) Phenotypic plasticity and experimental evolution. Journal of Experimental Biology, 209, 2344-2361.

Gaston, K.J., Blackburn, T.M. \& Gregory, R.D. (1999) Does variation in census area confound density comparisons? Journal of Applied Ecology, 36, 191-204.

Ghalambor, C.K., Huey, R.B., Martin, P.R., Tewksbury, J.J. \& Wang, G. (2006) Are mountain passes higher in the tropics? Janzen's hypothesis revisited. Integrative and Comparative Biology, 46, 5-17.

Ghalambor, C.K., McKay, J.K., Carroll, S.P. \& Reznick, D.N. (2007) Adaptive versus non-adaptive phenotypic plasticity and the potential for contemporary adaptation in new environments. Functional Ecology, 21, 394-407.

Gibbs, A.G. (1999) Laboratory selection for the comparative physiologist. Journal of Experimental Biology, 202, 2709-2718.

Gilchrist, G.W., Huey, R.B. \& Partridge, L. (1997) Thermal sensitivity of Drosophila melanogaster: evolutionary responses of adults and eggs to laboratory natural selection at different temperatures. Physiological Zoology, 70, $403-414$.

Harshman, L.G. \& Hoffmann, A.A. (2000) Laboratory selection experiments using Drosophila: what do they really tell us? Trends in Ecology and Evolution, 15, 32-36.

Hartl, D.L. (1980) Principles of Population Genetics. Sinauer Associates, Sunderland.

Hawes, T.C., Couldridge, C.E., Bale, J.S., Worland, M.R. \& Convey, P. (2006) Habitat temperature and the temporal scaling of cold hardening in the high Arctic collembolan, Hypogastrura tullbergi (Schäffer). Ecological Entomology, 31, 450-459.

Helmuth, B., Kingsolver, J.G. \& Carrington, E. (2005) Biophysics, physiological ecology, and climate change: does mechanism matter? Annual Review of Physiology, 67, 177-201.

Hochachka, P.W. \& Somero, G.N. (2002) Biochemical Adaptation. Mechanisms and Processes in Physiological Evolution. Oxford University Press, New York.

Hoffmann, A.A., Anderson, A. \& Hallas, R. (2002) Opposing clines for high and low temperature resistance in Drosophila melanogaster. Ecology Letters, 5, 614-618.

Hoffmann, A.A., Hallas, R.J., Dean, J.A. \& Schiffer, M. (2003b) Low potential for climatic stress adaptation in a rainforest Drosophila species. Science, 301, $100-102$.

Hoffmann, A.A. \& Parsons, P.A. (1988) The analysis of quantitative variation in natural populations with isofemale strains. Genetique, Selection, Evolution, 20, 87-98.

Hoffmann, A.A., Sørensen, J.G. \& Loeschcke, V. (2003a) Adaptation of Drosophila to temperature extremes: bringing together quantitative and molecular approaches. Journal of Thermal Biology, 28, 175-216.

Hoffmann, A.A. \& Watson, M. (1993) Geographical variation in the acclimation responses of Drosophila to temperature extremes. American Naturalist, 142, S93-S113.

Holway, D.A., Lach, L., Suarez, A.V., Tsutsui, N.D. \& Case, T.J. (2002) The causes and consequences of ant invasions. Annual Review of Ecology and Systematics, 33, 181-233.

Huey, R.B. \& Kingsolver, J.G. (1993) Evolution of resistance to high temperature in ectotherms. American Naturalist Supplement, 142, 21-46.

Kay, R.C.A. \& Whitford, W.G. (1978) Critical thermal limits of desert honey ants: possible ecological implications. Physiological Zoology, 51, 206-213.

Kelty, J.D. \& Lee, R.E. (1999) Induction of rapid cold hardening by cooling at ecologically relevant rates in Drosophila melanogaster. Journal of Insect Physiology, 45, 719-726.

Kelty, J.D. \& Lee, R.E. (2001) Rapid cold-hardening of Drosophila melanogaster (Diptera: Drosophilidae) during ecologically based thermoperiodic cycles. Journal of Experimental Biology, 204, 1659-1666.

Kimura, M.T. (2004) Cold and heat tolerance of drosophilid flies with reference to their latitudinal distributions. Oecologia, 140, 442-449.

Kingsolver, J.G. \& Huey, R.B. (1998) Evolutionary analyses of morphological and physiological plasticity in thermally variable environments. American Zoologist, 38, 545-560.

Klok, C.J. \& Chown, S.L. (2003) Resistance to temperature extremes in sub-Antarctic weevils: interspecific variation, population differentiation and acclimation. Biological Journal of the Linnean Society, 78, 401-414.

(C) 2008 The Authors. Journal compilation ( 2008 British Ecological Society, Functional Ecology, 23, 133-140 
Kristensen, T.N., Hoffmann, A.A., Overgaard, J., Sørensen, J.G., Hallas, J. \& Loeschcke, V. (2008) Costs and benefits of cold acclimation in field-released Drosophila. Proceedings of the National Academy of Sciences of the USA, 105, 216-221.

Kristensen, T.N., Loeschcke, V. \& Hoffmann, A.A. (2007) Can artificially selected phenotypes influence a component of field fitness? Thermal selection and fly performance under thermal extremes. Proceedings of the Royal Society of London B, 274, 771-778.

Krushelnycky, P.D., Joe, S.M., Medeiros, A.C., Daehler, C.C. \& Loope, L.L. (2005) The role of abiotic conditions in shaping the long-term patterns of high-elevation Argentine ant invasion. Diversity and Distributions, 11, 319_ 331.

Lee, R.E., Chen, C.-P. \& Denlinger, D.L. (1987) A rapid cold-hardening process in insects. Science, 238, 1415-1417.

Littell, R.C., Stroup, W.W. \& Freund, R.J. (2002) SAS for Linear Models. SAS Institute Inc., Cary, NC.

Loeschcke, V. \& Hoffmann, A.A. (2007) Consequences of heat hardening on a field fitness component in Drosophila depend on environmental temperature. American Naturalist, 169, 175-183.

Lutterschmidt, W.I. \& Hutchison, V.H. (1997a) The critical thermal maximum: history and critique. Canadian Journal of Zoology, 75, 1561-1574.

Lutterschmidt, W.I. \& Hutchison, V.H. (1997b) The critical thermal maximum: data to support the onset of spasms as the definitive end point. Canadian Journal of Zoology, 75, 1553-1560.

Mora, C. \& Maya, M.F. (2006) Effect of rate of temperature increase of the dynamic method on the heat tolerance of fishes. Journal of Thermal Biology, 31, 337-341.

Overgaard, J., Sørensen, J.G., Petersen, S.O., Loeschcke, V. \& Holmstrup, M (2006) Reorganization of membrane lipids during fast and slow cold hardening in Drosophila melanogaster. Physiological Entomology, 31, 328 335.

Parmesan, C. (2006) Ecological and evolutionary responses to recent climate change. Annual Review of Ecology, Evolution and Systematics, 37, 637-669.

Pigliucci, M., Murren, C.J. \& Schlichting, C.D. (2006) Phenotypic plasticity and evolution by genetic assimilation. Journal of Experimental Biology, 209, 2362-2367.

Pörtner, H.O. \& Knust, R. (2007) Climate change affects marine fishes through the oxygen limitation of thermal tolerance. Science, 315, 95-97.

Powell, S.J. \& Bale, J.S. (2006) Effect of long-term and rapid cold hardening on the cold torpor temperature of an aphid. Physiological Entomology, 31, 348 352.

Quinn, G.P. \& Keough, M.J. (2002) Experimental Design and Data Analysis for Biologists. Cambridge University Press, Cambridge.

Rako, L., Blacket, M.J., McKechnie, S.W. \& Hoffmann, A.A. (2007) Candidate genes and thermal phenotypes: identifying ecologically important genetic variation for thermotolerance in the Australian Drosophila melanogaster cline. Molecular Ecology, 16, 2948-2957.

Rako, L. \& Hoffmann, A.A. (2006) Complexity of the cold acclimation response in Drosophila melanogaster. Journal of Insect Physiology, 52, 94 104.

Riska, B., Prout, T. \& Turelli, M. (1989) Laboratory estimates of heritabilities and genetic correlations in nature. Genetics, 123, 865-871.

Roura-Pascual, N., Suarez, A.V., Gómez, C., Pons, P., Touyama, Y., Wild, A.L. \& Peterson, A.T. (2004) Geographical potential of Argentine ants (Linepithema humile Mayr) in the face of global climate change. Proceedings of the Royal Society of London B, 271, 2527-2534.

Schilman, P.E., Lighton, J.R.B. \& Holway, D.A. (2007) Water balance in the Argentine ant (Linepithema humile) compared with five common native ant species from southern California. Physiological Entomology, 32, 1-7.

Sgrò, C.M. \& Partridge, L. (2000) Evolutionary responses of the life-history of wild-caught Drosophila melanogaster to two standard methods of laboratory culture. American Naturalist, 156, 341-353.

Sinclair, B.J. (2001) Field ecology of freeze tolerance: interannual variation in cooling rates, freeze-thaw and thermal stress in the microhabitat of the alpine cockroach Celatoblatta quinquemaculata. Oikos, 93, 286-293.

Somero, G.N. (2005) Linking biogeography to physiology: evolutionary and acclimatory adjustments of thermal limits. Frontiers in Zoology, 2, 1-9.
Sørensen, J.G., Nielsen, M.M. \& Loeschcke, V. (2007) Gene expression profile analysis of Drosophila melanogaster selected for resistance to environmental stressors. Journal of Evolutionary Biology, 20, 1624-1636.

Stevenson, R.D. (1985) The relative importance of behavioral and physiological adjustments controlling body temperature in terrestrial ectotherms. American Naturalist, 126, 362-386.

Terblanche, J.S., Deere, J.A., Clusella Trullas, S., Janion, C. \& Chown, S.L. (2007a) Critical thermal limits depend on methodological context. Proceeding. of the Royal Society of London B, 274, 2935-2942.

Terblanche, J., Klok, C.J., Krafsur, E.S. \& Chown, S.L. (2006) Phenotypic plasticity and geographic variation in thermal tolerance and water loss of the tsetse Glossina pallidipes (Diptera: Glossinidae): implications for distribution modelling. American Journal of Tropical Medicine and Hygiene, 74, 786794

Terblanche, J.S., Marais, E. \& Chown, S.L. (2007b) Stage-related variation in rapid cold hardening as a test of the environmental predictability hypothesis. Journal of Insect Physiology, 53, 455-162.

Tsutsui, N.D., Suarez, A.V. \& Grosberg, R.K. (2003) Genetic diversity, asymettrical aggression, and recognition in a widespread invader species. Proceedings of the National Academy of Sciences of the USA, 100, 1078-1083.

Tsutsui, N.D., Suarez, A.V., Holway, D.A. \& Case, T.J. (2000) Reduced genetic variation and the success of an invasive species. Proceedings of the National Academy of Sciences of the USA, 97, 5948-5953.

Walters, A.C. \& Mackay, D.A. (2003) An experimental study of the relative humidity preference and survival of the Argentine ant, Linepithema humile (Hymenoptera, Formicidae): comparisons with a native Iridomyrmex species in South Australia. Insectes Sociaux, 50, 355-360.

West-Eberhard, M.J. (2003) Developmental Plasticity and Evolution. Oxford University Press, New York.

Wilson, A.J. (2008) Why $h_{2}$ does not always equal $V_{\mathrm{A}} / V_{\mathrm{P}}$ ? Journal of Evolutionary Biology, 21, 647-650.

Witt, A.B.R. \& Giliomee, J.H. (1999) Soil-surface temperatures at which six species of ants (Hymenoptera: Formicidae) are active. African Entomology, 7, 161-164.

Worland, M.R. (2005) Factors that influence freezing in the sub-Antarctic springtail Tullbergia antarctica. Journal of Insect Physiology, 51, 881-894.

Yassin, A., Abou-Youssef, A.Y., Bitner-Mathe, B., Capy, P. \& David, J.R. (2007) Developmental stress in wild-living drosophilids inferred from biometry: metric and meristic traits react differently to heterogeneous environmental conditions. Ecological Entomology, 32, 698-706.

Received 25 March 2008; accepted 12 August 2008

Handling Editor: Frank Messina

\section{Supporting Information}

Additional Supporting Information may be found in the online version of this article:

Fig. S1. Critical thermal maxima in Drosphila melanogaster.

Fig. S2. Critical thermal minima in Drosphila melanogaster.

Fig. S3. Critical thermal maxima in Linepithema humile.

Fig. S4. Critical thermal minima in Linepithema humile.

Please note: Wiley-Blackwell are not responsible for the content or functionality of any supporting materials supplied by the authors. Any queries (other than missing material) should be directed to the corresponding author for the article. 